\title{
The Optimal Design of Creative Flat Folding Table
}

\author{
Xianhao Teng \\ School of Electric Power Engineering, North China Electric Power University, Baoding 071000, \\ China.
}

18331136327@163.com

Keywords: Space Geometry; Linear Optimization; Lingo Matlab

\begin{abstract}
In this article, we use space geometry and linear optimization to set up the creative flat folding table of the optimal parameters of the model, and synthetically use Lingo and Matlab software to solve the model.

In order to describe the problem, we first establish a rectangular coordinate system. Then,we use the lateral angle of table leg and the ground level to describe the dynamic changes of the folding table,and use the knowledge of spatial geometry to solve the slot length table leg batten and the process of any position at the bottom of the table leg batten coordinates.Finally, with the help of Matlab software drawing function, we obtain the form of any position folding table, and select several positions of the form to show the dynamic change process. On this basis, we design the processing parameters of folding table processing,such as required length, root number and the length of the leg of the table,and use the Matlab fitting toolbox of CFTool to make the mathematical description of the foot of the table edge line.
\end{abstract}

\section{Introduction}

Given a rectangular plate size of $120 \mathrm{~cm} * 50 \mathrm{~cm} * 3 \mathrm{~cm}$, every piece of wood is $2.5 \mathrm{~cm}$ wide. reinforced connection table leg batten is fixed on the center position of the leg of the table outside the wood and folded after the height of the table is $53 \mathrm{~cm}$. Try to establish the model to describe the dynamic change process of the folding table, folding table design and processing parameters are given on the basis of this (for example, table leg batten slotted length) and the foot of the table edge mathematical description.

\section{Model}

\section{Question Analysis.}

First, we establish a space rectangular coordinate system based on flat folding table. Then, we get each leg of the table top position and the length of wood. Next, we get the length of the groove by using the relevant knowledge of the geometry of the solution space and in any position at the bottom of the table leg batten coordinates. Finally, with the help of Matlab software, the dynamic process of folding table is described. On this basis, by using the Matlab toolbox of CFTool we design the processing parameters of folding table processing,such as required length, root number and the length of the leg of the table.

\section{Model building and solving.}

In the initial state of the rectangular plate, that is the whole process of change in the circle of the desktop plane as a plane.we establish the spatial rectangular coordinate system.As shown in the figure1, the $\mathrm{Z}$ axis is vertical paper outward. 

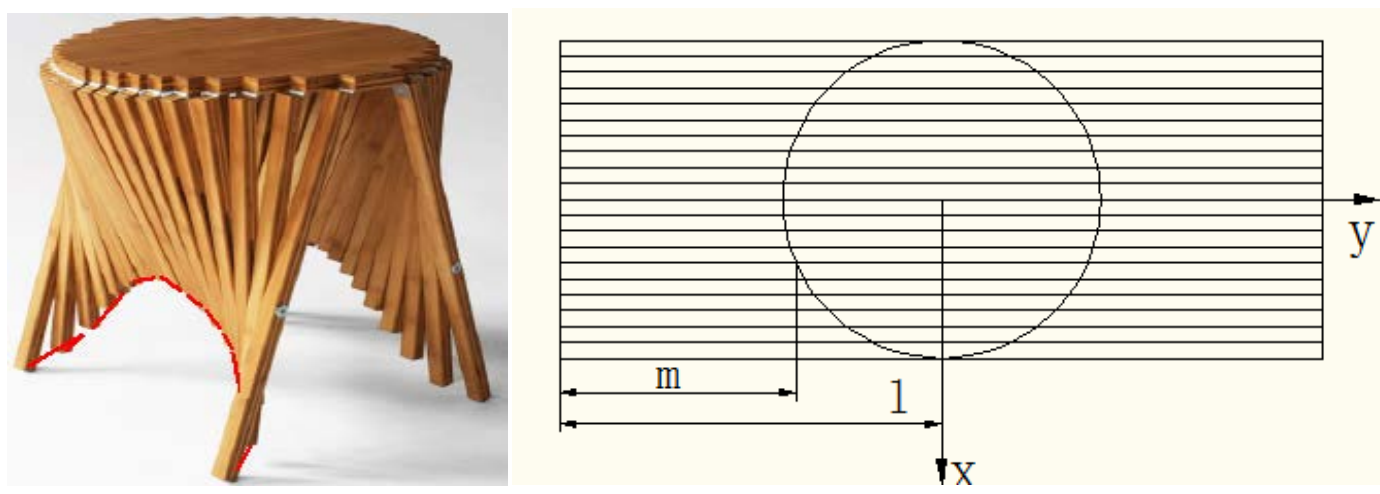

Figure1. Schematic diagram of flat table

A rectangular plate length $2 \mathrm{~L}$, width $2 \mathrm{R}$, thickness $\mathrm{h}$, each piece of wood width is $\mathrm{W}$, the height of the table is $\mathrm{H}$.Then the circular desktop radius is $\mathrm{R}$.

The number of folding table in each group is:

$N=2 R / W$;

Because the table top of the folding table is round, the edge line of the table satisfies the equation:

$\left\{\begin{array}{l}x_{0}^{2}+y_{0}^{2}=R^{2} \\ z=0\end{array}\right.$

Any take a leg of the table with the wood, the width of the midpoint position replace the position and set the endpoint coordinates $\left(x_{i}, y_{i}\right)$. Because the endpoint is located in the edge of the desktop line, the edge of the desktop coordinates satisfy the curve equation.Then the edge curve equation:

$\left\{\begin{array}{l}x_{i}^{2}+y_{i}^{2}=R^{2} \\ z_{i}=0\end{array}\right.$
$x_{i}=R-\frac{2 i-1}{2} \cdot W, i=1,2, \cdots, N ;$

The lateral leg batten length is $l$, one of the legs of the table is $\mathrm{m}_{\mathrm{i}}$, so we can calculate anyone of the table leg to meet the length of wood:

$m_{i}=l-\left|y_{i}\right|$

The angle between the outer legs sticks at a time and level of the ground is $\alpha$.Any angle between the legs and the level of the ground is $\beta_{i}$.One leg of the table bottom to the top of the wood wood slot length is $a_{i}$.

$\alpha=\arcsin H / l$;

In the triangle $\mathrm{AOB}$, according to the cosine theorem:

$a_{i}=\sqrt{y_{i}^{2}+(l / 2)^{2}-2 \times y_{i} \cdot(l / 2) \cdot \cos \alpha}$;

$\beta_{i}=\arccos \left(\frac{y_{i}^{2}+a^{2}-(l / 2)^{2}}{2 \cdot a \cdot y_{i}}\right)$

Any wooden table leg bottom coordinates: $\left(x_{i},-y_{i}+m_{i} \cos \beta_{i},-m_{i} \sin \beta_{i}\right)$.

We use the Matlab fitting toolbox of CFTool to make the mathematical description of the foot of the table edge line. 

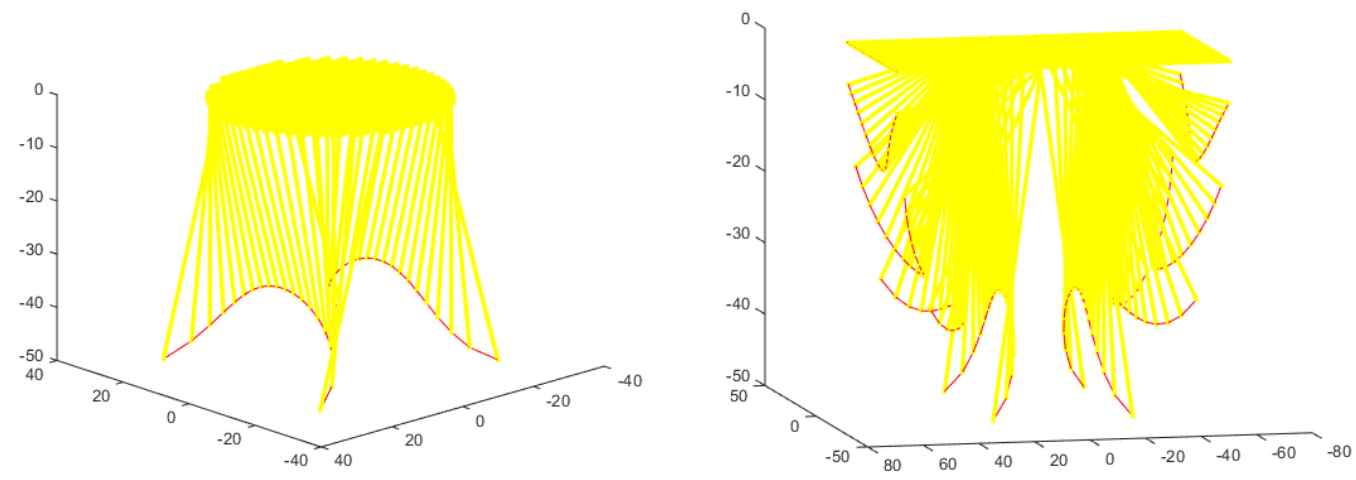

Figure2.Dynamic diagram of folding table in three dimensional space

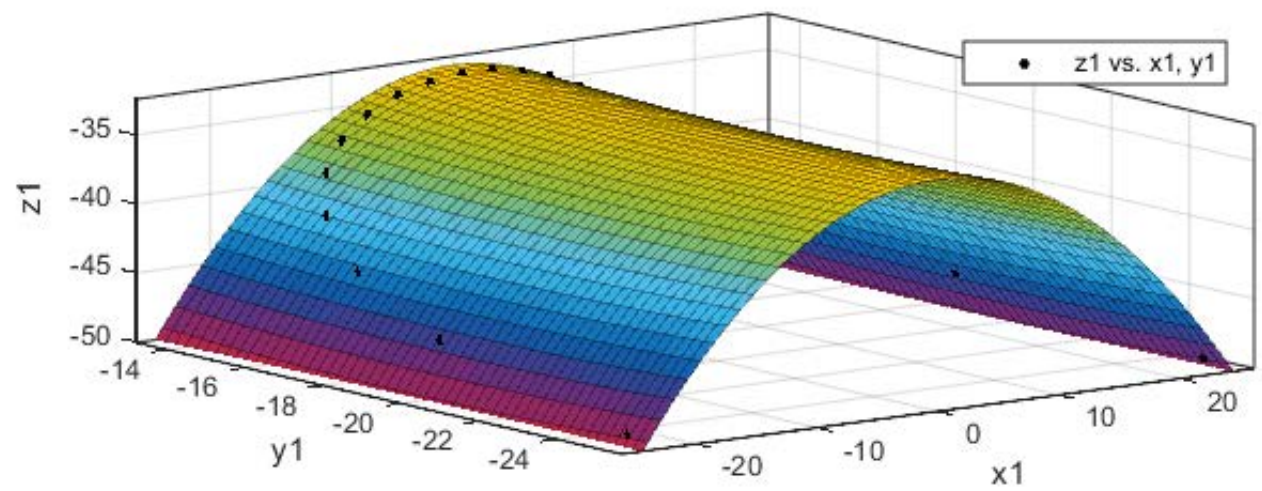

Figure3.Mathematical description of the edge line of the table

The use of Matlab fitting toolbox CFTool and the polynomial fitting, the order of $\mathrm{x}, \mathrm{y}$ are 2.And we get the edge of the table to fit the foot line

$\mathrm{z}=-28.17+1.913 \mathrm{e}-15 * \mathrm{x}+0.5509 * \mathrm{y}-0.02823 * \mathrm{x}^{\wedge} 2+9.856 \mathrm{e}-17 * \mathrm{x}^{*} \mathrm{y}+0.01377 * \mathrm{y} \wedge 2$

The coefficient of $\mathrm{x}$ is $1.913 \mathrm{e}-15$.The coefficient of $\mathrm{x}^{*} \mathrm{y}$ is $9.856 \mathrm{e}-17$, and can be considered as 0 .

So we fit the result for:

$\mathrm{z}=-28.17+0.5509 * \mathrm{y}-0.02823 * \mathrm{x}^{\wedge} 2+0.01377 * \mathrm{y}^{\wedge} 2$

\section{Conclusions}

Through the analysis of the above results, SSE $=0.004325$, R-square $=1$, it is proved that the fitting effect is good.

According to the height of the folding table, the shape of the edge line of the desktop and the approximate shape of the edge of the table, the company can get the shape and size of the plate material and the optimum design parameters.

\section{References}

[1] Phantipa Thipwiwatpotjana, Weldon A. Lodwick, A relationship between probability interval and random sets and its application to linear optimization with uncertainties, Fuzzy Sets and Systems, Volume 231, 16 November 2013.

[2] Laura E. Condon, Reed M. Maxwell, Implementation of a linear optimization water allocation algorithm into a fully integrated physical hydrology model, Advances in Water Resources, Volume 60, October 2013, Pages 135-147.

[3] Marco Lolli, Sarah Narramore, Colin W.G. Fishwick, Klaus Pors, Refining the chemical toolbox to be fit for educational and practical purpose for drug discovery in the 21st Century, Drug 
Discovery Today, Volume 20, Issue 8, August 2015, Pages 1018-1026.

[4] Giuliano Casale, Eddy Z. Zhang, Evgenia Smirni, KPC-Toolbox: Best recipes for automatic trace fitting using Markovian Arrival Processes, Performance Evaluation, Volume 67, Issue 9, September 2010, Pages 873-896, ISSN 0166-5316. 